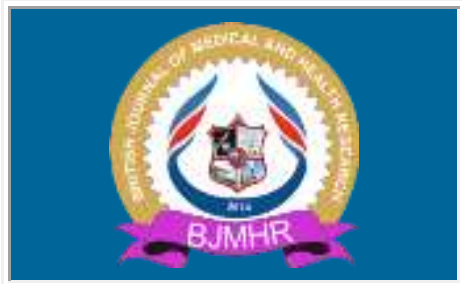

\title{
BJMHR
}

British Journal of Medical and Health Research Journal home page: www.bjmhr.com

\section{Role of Clinical Pharmacist in Patients with Asthma and Chronic Obstructive Pulmonary Disease by Intervention and Patient Counseling.}

\author{
Syed.Allahuddin ${ }^{1}$, Dr.S.Parveen ${ }^{2 *}$, Guru Prasad ${ }^{3}$, Chandra Mohan ${ }^{4}$. \\ 1 Pharm-D, Department of Pharmacy Practice, Rajiv Gandhi Institute of Medical \\ Sciences, Kadapa, Andhra Pradesh, India \\ *2 Assistant Professor, Department of Pharmacy Practice, Rajiv Gandhi Institute of \\ Medical Sciences, Kadapa, Andhra Pradesh, India \\ 3 Pharm-D, Department of Pharmacy Practice, Rajiv Gandhi Institute of Medical \\ Sciences, Kadapa, Andhra Pradesh, India \\ 4 Pharm-D, Department of Pharmacy Practice, Rajiv Gandhi Institute of Medical \\ Sciences, Kadapa, Andhra Pradesh, India
}

\begin{abstract}
The aim of the study was to improve the standard of living in patients with Asthma and Chronic obstructive pulmonary disease by intervention and patient counseling. This Prospective interventional study was carried out in general medicine department RIMS for 6 months. Both old and new asthma and COPD Patients were included. Statistical Analysis was performed to find the statistical significance difference among all the study groups. In our study we had recruited 100 patients of which we categorized based on gender, age, occupation and risk factors, the majority of patients in the gender were females in asthma and males in COPD, age group between 51-60( $\mathrm{n}=33,55 \%)$, in occupation coolie group $(\mathrm{n}=43,71.66 \%)$, and in risk factor were smoker $(n=52,54.16 \%)$. This study concluded that the clinical pharmacist can play a positive role in the control of patients, to prevent recurrences, reduce progression of disease and ultimately minimize hospitalization.
\end{abstract}

Keywords: Clinical pharmacist; Asthma; Intervention; patient counseling. 


\section{INTRODUCTION}

More than 2000 years ago, Hippocrates used the word asthma to describe episodic shortness of breath. ${ }^{[1]}$ The Global Initiative for Asthma (GINA) guidelines gives the definition of asthma: "Asthma is a Chronically inflamed airways are hyper responsive; they become obstructed and airflow is limited by bronchoconstriction, mucus plugs, and increased inflammation."[2] According to the Global Initiative for Chronic Obstructive Lung Disease group (GOLD) guidelines is as follows: "COPD is a disease state characterized by airflow limitation that is not fully reversible. The airflow limitation is usually both progressive and associated. ${ }^{[3]}$ Throughout the world approximately 334 million people are suffering from asthma. ${ }^{[4]}$ In each decade prevalence is increased by $50 \% .^{[5]}$ Asthma is the 14th most important disorder in the world in terms of the extent and duration of disability. ${ }^{[4]}$ Chronic obstructive pulmonary disease is major cause of morbidity and mortality across globe. According to WHO estimates 65 million have moderate to severe COPD. More than 3 million people died in 2005, 5\% of all death globally. 3rd leading cause of death by 2030. ${ }^{[6]}$ According to the World Health Organization, adherence is the extent to which a person's behaviour (e.g., taking medications, following a diet and/or executing lifestyle changes) corresponds with agreed-upon recommendations from a health care provider. $^{[7]}$ According to the encyclopedia of biopharmaceutical statistics, adherence is defined as, a) Willingness to follow the prescribed course of treatment. b) The act of complying with a wish, request or demand. ${ }^{[8]}$ Medication compliance is important in managing the disease. Non-compliance can lead to lack of drug efficacy. A large number of interventions to improve patient adherence have been studied. Most of these have been patient-oriented and educational. Oral instructions are the most frequently studied interventions, followed by written instructions and educational leaflets. Other commonly studied interventions are those directed at modifying patient behaviour. Very few studies have addressed the issue of provider-focused interventions. There is no evidence till date that anyone method improves medication adherence better than another. ${ }^{[9]}$

Interventional strategies can be provider-targeted or patient-focused. Provider targeted interventions include the education of health care workers including the treating physician, community pharmacists and nurses. Patient targeted interventions include various education strategies with oral or written instructions audiovisual materials. Education can be improved to patients individually or with their family members or in patient groups. Interventions which target the behaviour of patient are also useful. These include medication doses, verbal agreement with patients, tailoring the regimen to suit the patient's convenience. Counseling involves providing verbal information to patients about their illness and its treatment. It may 
entail the use of various methods, but true counseling is a two-way process and involves listening as well as talking. ${ }^{\text {9] }}$

\section{Research methodology:}

A Prospective interventional study was conducted for 6 months, sample size was 100 patients who were diagnosed as asthma and COPD, patients were enrolled in the study based on inclusion criteria who were both old and new asthma and COPD patients with age group between 30-70 years and who were willing to participate in the study, patients were excluded those who were pregnant, lactating women, pediatrics and both old and new asthma and COPD patients with co-morbidities.

\section{RESULTS AND DISCUSSION}

Participant characteristics

Altogether 100 patients were participated in this study, and the response was $100 \%$. Of these, $43 \%(n=43)$ patients were asthma and 57\%(n=57) patients were COPD.

Table 1 shows the participants were divided into 2 groups by gender i.e., male and female, in asthma 18(30\%) were males and 25(41.66\%) were females, in COPD 45(75\%) were males and $12(20 \%)$ were females. The majority of patients in asthma were females $25(41.66 \%)$, and in COPD were males $45(75 \%)$.

Table:1 Gender wise distribution of patients $(n=100)$

\begin{tabular}{lllll}
\hline & \multicolumn{2}{l}{ Asthma } & COPD \\
\hline Gender & Male & Female & Male & Female \\
No of Patients & 18 & 25 & 45 & 12 \\
Percentage & $30 \%$ & $41.66 \%$ & $75 \%$ & $20 \%$ \\
\hline
\end{tabular}

Table 2 shows the participants were divided into 4 groups by age: $31-40(n=15,25 \%), 41$ $50(n=20,33.33 \%), 51-60(n=33,55 \%), 61-70(n=32,53.33 \%)$. The majority of patients in the age group between $51-60(\mathrm{n}=33,55 \%)$.

Table 3 shows the participants were divided into 4 groups based on occupation: coolie $(n=43$, $71.6 \%)$, farmer( $(n=20,33.3 \%)$, house wife $(n=15,25 \%)$ and others $(n=22,36.6 \%)$. The majority of patients were in the coolie group $(n=43,71.6 \%)$.

Table:2 Age wise distribution of patients $(n=100)$

\begin{tabular}{lllll}
\hline Age & $\mathbf{3 1 - 4 0}$ & $\mathbf{4 1 - 5 0}$ & $\mathbf{5 1 - 6 0}$ & $\mathbf{6 1 - 7 0}$ \\
No of patients & 15 & 20 & 33 & 32 \\
Percentage & $25 \%$ & $33.33 \%$ & $55 \%$ & $53.33 \%$ \\
\hline
\end{tabular}

Table 3 : Occupation wise distribution of patients $(n=100)$

\begin{tabular}{lllll}
\hline Occupation & Coolie & Farmer & House Wife & Others \\
\hline No of patients & 43 & 20 & 15 & 22 \\
Percentage & $71.6 \%$ & $33.3 \%$ & $25 \%$ & $36.6 \%$ \\
\hline
\end{tabular}


Table 4: Types of Risk Factors $(n=96)$

\begin{tabular}{lll}
\hline Risk factor & No of patients & Percentage \\
\hline Smoker & 52 & $54.16 \%$ \\
Alcoholic Only & 11 & $11.45 \%$ \\
Alcoholic \& Smoker & 21 & $21.87 \%$ \\
Beetle nut Chewer & 12 & $12.5 \%$ \\
TOTAL & $\mathbf{9 6}$ & $\mathbf{9 6 \%}$ \\
\hline
\end{tabular}

Table 4 shows the participants were divided into 4 groups by risk factors: $\operatorname{smoker}(\mathrm{n}=52$, $54.16 \%)$, alcoholic only $(\mathrm{n}=11,11.45 \%)$, alcoholic \& smoker( $\mathrm{n}=21,21.87 \%)$, beetle nut chewer( $(n=12,12.5 \%)$. The majority of patients in the risk factor were smoker $(n=52,54.16 \%)$.

\section{DISCUSSION:}

Asthma and COPD are one of the diseases with large number of people affected around the world, even in India, 334 million people and 65 million people worldwide were affected by asthma and COPD respectively.

Total number of patients we had recruited in our study were 100, of which the prevalence rate of bronchial asthma was more in females $25(41.66 \%)$ than in males $18(30 \%)$ which showed similarity with the study conducted by K V Ramanath et al., ${ }^{3}$ and prevalence of COPD was more in males $45(75 \%)$ than in females 12 (20\%) which showed similarity with the study conducted by Ajay R Fugate et al. ${ }^{[10]}$

As per our study it was found that patients with age group of 51-60yrs 33 (55\%) were more vulnerable to asthma and COPD which showed similarity with the study conducted by Frode Gallefoss et al. ${ }^{[11]}$

We found that Coolie $43(71.66 \%)$ were suffering with asthma and COPD more when compared to other occupation people. As our study site was Govt. set up so consultation of Coolie patients were much high when compared to other occupation people and as they were illiterates and leading unhealthy life style they were not able to control risk factors and also we found that farmers $20(33.33 \%)$ were next to that group which showed similarity with the study conducted by K V Ramanath et al. ${ }^{[4]}$

As per our study it was found that the predominant risk factors for asthma and COPD was smoking 52(54.16\%) which showed similarity with the study conducted by Thomas Reema et al. ${ }^{[12]}$ and next to that group we found the alcoholic and smoker as a risk factor $21(21.87 \%)$ which showed similarity with the study conducted by Kabila et al. ${ }^{[13]}$

\section{Role of Clinical Pharmacist:}

There are opportunities in every type of pharmacy practice to improve patient's adherence and therapeutic outcomes, and pharmacists must embrace and act on them. The pharmacist must approach each patient individually to determine the level of adherence and what barriers may 
exist that are preventing the patient from taking his or her medication appropriately. Education, while helpful, was usually not enough to persuade the patient to comply with the physician's drug orders. Information must be presented in clear, easy-to-understand language, and the patient must understand not only the benefits of adherence, but the repercussions of nonadherence. Also, positive reinforcement goes a long way; patients who feel empowered and cared are to play an active role in their treatment. Dosing simplification and minimization of adverse effects are extremely successful strategies for improving adherence. When filling a prescription, the pharmacist should do a quick review to see whether the dosing schedule is as simple as possible. The pharmacist should inquire frequently about any adverse effects the patient is experiencing and then consult the physician regarding suggested alternatives. Reminder calls, texts, or e-mails are helpful for many patients, especially those with busy lifestyles. The more trust the patient has in the pharmacist, the more he or she will open up and disclose any apprehensions or difficulties about taking his or her medication. Only then can the pharmacist play an integral role in improving a patient's adherence. ${ }^{[14]}$

\section{CONCLUSION:}

This study concluded that the clinical pharmacist can play a positive role in the control of patients with chronic respiratory diseases and counseling should be conducted to emphasize and re-emphasize the importance and standard of living, to prevent recurrences, reduce progression of disease and ultimately minimize hospitalization.

\section{Limitations:}

1. Patients regular follow up (some patients were not came).

2. Sample patients size was less (100 patients).

3. Limited study period (6 months).

\section{Conflict of interest:}

The authors have no conflict of interest to declare.

\section{Authors' contributions:}

AS and SP designed the study, conducted data collection and performed data analysis. GP and CM provided logistical support and performed the final review of results. AS wrote the initial and final draft of the article. All authors have critically reviewed and approved the final draft and are responsible for the content and similarity index of the manuscript.

\section{ACKNOWLEDGMENT:}

Special thanks to all patients who participated in this study, as well as the nurses of the Hospital RIMS who assisted us in making the research successful. 


\section{REFERENCES:}

1. Text book of Robbins \& Catran pathologic basis of disease -7th edition -2005 published Elsevier- Chapter 15- page no:790-791.

2. Joseph T. Dipiro-pharmacotherapy A pathophysiologic approach- 7thedition-published by MC Graw Hill- 1999-chapter 28,29 -page no:463,464,496,500.

3. Elisabeth Stahl. Health related quality of life in COPD \& Asthma - Discriminative and evaluative aspects. Department of respiratory medicine and allergolog ,Lund University, Sweden.26 November, 2004-page no:11,15-6.

4. K.V . Ramanath et al. "A study on medication adherence \& QOL in asthma \& COPD of rural population in a tertiary care hospital. Indo global journal of pharmaceutical sciences",2011;1(4): 315-327.

5. The Global Asthma report 2014-www.globalasthmanetwork.org.-page no:20.

6. COPD: Indian guidelines and ahead the road Lung India 2013,July-Sep-30(3): 175-77.

7. World Health Organization. Adherence to long-term therapies: evidence for action.January2003.Available:www.who.int/entity/chp/knowledge/publications/adher ence_full_report.pdf (accessed November 4, 2011).

8. Iona Dana ALEXA, Simona STOCIA et al. Non-adherence in a large population of elderly patients with cardiovascular disease. MAEdica-a journal of clinical medicine 2006 ; Volume1, No-3: pg.no:14-15.

9. Parthasarathi G, Hansen KN, Nahata MC: A Textbook of Clinical Pharmacy Practice:2nd edition. Hyderabad: Universities Press(India) Private Limited; 2012. pg.no:74-84,222.

10. Ajay R Fugate et al., prospective study of medication adherence pattern in Chronic obstructive pulmonary disease and Asthma patient's in tertiary care hospital teaching. Indian Journal of Pharmacy Practice, Apr-Jun, 2015, Vol 8, Issue 2,pg no:78-83.

11. Frode Gallefoss et al., Quality of life assessment after patient education in a randomized controlled study on Asthma and Chronic obstructive pulmonary disease. American Journal Of Respiratory And Critical Care Medicine. 1999, Vol 159; pg no:812-817.

12. Thomas Reema et al., Impact of clinical pharmacist intervention on Knowledge, Attitude and Practice (KAP) of patients with Chronic obstructive pulmonary disease. International journal of pharmacy and pharmaceutical sciences.2010,vol-2, issue4;pgno:54-57.

13. Kabila B , Sankar V-Risk factor assessment study for Bronchial asthma among the rural people -Indian Journal of pharmacy practice - Jul to Sep,2011, Volume 4-Issue3. 
14. Suzanne Albrecht, freelance, Woodstock. The Pharmacist's Role in Medication Adherence: US Pharm. 2011; 36(5): 45-48.

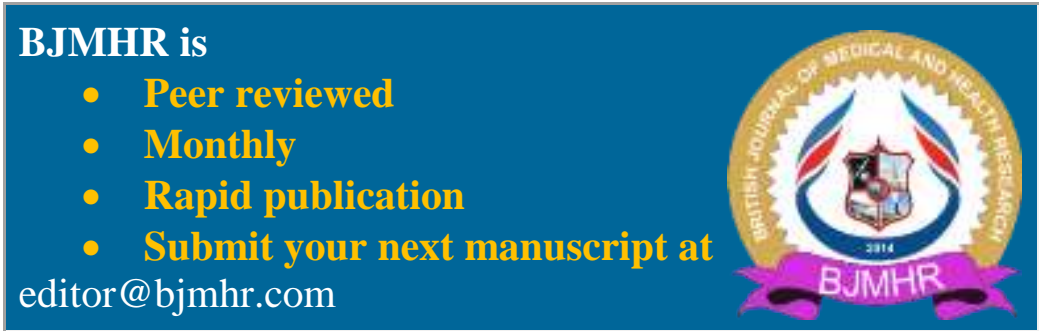

